\title{
Properties of the Solute-Stationary Liquid Interactions in Gas Liquid Chromatography
}

\author{
Hideko KAWAKI \\ Pharmaceutical Research and Technology Institute, Kinki University; 3-4-1 Kowakae, Higashi-Osaka 577-8502, Japan.
}

Received November 12, 2007; accepted December 14, 2007; published online December 18, 2007

The solute-stationary liquid interaction in gas liquid chromatography (GLC) was determined using Eyring's model. The interaction was determined to be the physical adsorption. The descriptor $\sigma_{\mathrm{M}}$ was derived and estimated by van der Waals interactions. The $\mathrm{CH} / \pi$ interaction energies were calculated by Tsuzuki et al. using the high-level $a b$ initio calculations. The $\mathrm{CH} / \pi$ interaction energy was concluded to consist of the dispersion energy $\left(E_{\mathrm{dis}}\right)$ rather than the electrostatic $\left(E_{\mathrm{es}}\right)$ and charge-transfer $\left(E_{\mathrm{ct}}\right)$ energies. These energies were in good agreement with our descriptor $\sigma_{\mathrm{M}}$. Furthermore, the macroscopic $\sigma_{\mathrm{M}}$ also had microscopic support through the weak $\mathrm{CH} / \pi$ interactions. In substituted benzenes, regression analyses were carried out using $\sigma_{M}$ for the relative retention values, $\log \gamma$, as a measure of the solute-stationary liquid interaction. The analyses revealed good results under non-polar conditions. The $\log \gamma$ values therefore consisted primarily of contributions from the dispersion interaction and the $\mathrm{CH} / \pi$ complex. Moreover, these values were useful when added to the electrostatic term (our descriptor $\sigma_{\text {es }}$ ) for polar solutes. That is, the $\log \gamma$ values were estimated by the regression analyses using both $\sigma_{\mathrm{M}}$ and $\sigma_{\mathrm{es}}$, and were in good agreement with the predicted values.

Key words physical adsorption; van der Waals interaction; $\mathrm{CH} / \pi$ interaction; gas liquid chromatography; solute-stationary liquid interaction; substituted benzene

Noncovalent interactions are very important in molecular recognition of biochemistry, molecular crystals, ${ }^{1-3)}$ and hostguest complexes. ${ }^{4)}$ In addition, they play a key role in determining the molecular orientation in molecular assemblies. The weak interaction between the $\mathrm{C}-\mathrm{H}$ bond and the aromatic $\pi$ system called the $\mathrm{CH} / \pi$ interaction, ${ }^{5)}$ has been determined to be a primary contributor to the electrostatic and charge-transfer terms ${ }^{5,6)}$ based on primary ab initio calculations using a small basis set. In recent years, high-level $a b$ initio calculations of the typical $\mathrm{CH} / \pi$ complex have shown that dispersion is a major source of attraction. ${ }^{7-9)}$ MP2 interaction energy depends strongly on the basis set and small basis sets $\left(6-31 \mathrm{G}^{*}, 6-311 \mathrm{G}^{* *}\right.$ and cc-pVDZ) greatly underestimate the attraction. Therefore, MP2/cc-pVXZ $(X=T$ or $\mathrm{Q})$ or MP2/aug-cc-pVXZ (X=D or T) level calculations are necessary for quantitative evaluation of the dispersion energy. ${ }^{10)}$ The estimated $\operatorname{CCSD}(\mathrm{T})$ interaction energy for a methane-benzene complex as an example of a typical $\mathrm{CH} / \pi$ interaction at the basis set limit $\left(D_{\mathrm{e}}\right)$ was reported to be $-1.43 \mathrm{kcal} \mathrm{mol}^{-1}$ by Shibasaki et al. ${ }^{10)}$ Takahashi et al. ${ }^{11)}$ reported a value of $-1.01 \mathrm{kcal} \mathrm{mol}^{-1}$ for the same structure using MP2/6-311++G (d,p) level calculations. The binding energy $D_{\mathrm{o}}$ was estimated by the $D_{\mathrm{e}}$ and vibrational zero-point energy. This value showed that the former $D_{0}\left(1.13 \mathrm{kcal} \mathrm{mol}^{-1}\right)$ was close to the experimental $D_{\mathrm{o}}\left(1.03-1.13 \mathrm{kcal} \mathrm{mol}^{-1}\right)$. Furthermore, DEF calculations were discussed using BLYP, B3LYP, PW91 and PBE functions were determined to be in appropriate for the quantitative evaluation of the $\mathrm{CH} / \pi$ interaction energy. ${ }^{12-14)}$ The calculated energy $E_{\mathrm{CCSD}(\mathrm{T})(\mathrm{limit})}$ was determined to be appropriate for a quantitative evaluation of the $\mathrm{CH} / \pi$ interaction.

In the solute-staitonary liquid interaction of gas liquid chromatography, the entropy changes $\Delta \Delta S_{\mathrm{s}}^{\mathrm{o}}$ of dissolution were determined to be correlated to the descriptor $\sigma_{\mathrm{M}}$ in order to evaluate a physical adsorption using Eyring's model. ${ }^{15,16)}$ These findings supported the fact that van der Waals interactions were responsible for the formation $\mathrm{CH} / \pi$ complexes between $\mathrm{C}-\mathrm{H}$ bond of squalane as the stationary liquid and the aromatic $\pi$ system of the solute. Herein, we discuss the physical origin of the microscopic conditions under which the descriptor $\sigma_{\mathrm{M}}$ is correlated to the $\mathrm{CH} / \pi$ interaction energy introduced into the high-level $a b$ initio calculations.

\section{Experimental}

Relative Retention Value $\log \gamma \quad$ The $\log \gamma$ defined by Eq. $1 .{ }^{17)}$

$$
\begin{aligned}
\log \gamma= & \log \left[t_{\mathrm{R}}(\mathrm{B}) / t_{\mathrm{R}}(\mathrm{A})\right]=-\left[\Delta H_{\mathrm{s}}{ }^{\circ}(\mathrm{B})-\Delta H_{\mathrm{s}}^{\circ}(\mathrm{A})\right] / 2.303 R T \\
& +\left[\Delta S_{\mathrm{s}}{ }^{\circ}(\mathrm{B})-\Delta S_{\mathrm{s}}{ }^{\circ}(\mathrm{A})\right] / 2.303 R
\end{aligned}
$$

Where $t_{\mathrm{R}}(\mathrm{A})$ and $t_{\mathrm{R}}(\mathrm{B})$ are the retention times of the reference and substituted benzenes, respectively. $\Delta H_{\mathrm{s}}^{\mathrm{o}}$ and $\Delta S_{\mathrm{s}}^{\mathrm{o}}$ denote the enthalpy and entropy of dissolution of A and B. All data for $\log \gamma$ and the thermodynamic parameters were cited in references, ${ }^{18-20)}$ and the regression analyses were carried out using the statistical program. ${ }^{21)}$

Descriptors $\sigma_{\mathrm{M}}$ and $\sigma_{\mathrm{es}}$ for Regression Analysis The descriptor $\sigma_{\mathrm{M}}$ was derived from the Eyring's method: The activated translational entropy change $\Delta \Delta S_{\mathrm{ABC}}^{\dagger}$ for Eyring's equation ${ }^{15)}$ is given by the following equation, when there is the interaction between the solutes (A and $\mathrm{B}$ are the reference and its derivatives) and the non-polar stationary liquid (where $C$ is constant).

$$
\begin{aligned}
& \Delta S_{\mathrm{AC}}^{\dagger}=-R \ln \left[\left(2 \pi m_{\mathrm{A}} k T \mathrm{e}\right)^{3 / 2} / h^{3}\right] \\
& \Delta S_{\mathrm{BC}}^{\dagger}=-R \ln \left[\left(2 \pi m_{\mathrm{B}} k T \mathrm{e}\right)^{3 / 2} / h^{3}\right]
\end{aligned}
$$

Where $R, k, T$ and $h$ are the gas constant, Boltzmann's constant, absolute temperature and Plank's constant, respectively.

$$
\Delta \Delta S_{\mathrm{ABC}}^{\dagger}=\Delta S_{\mathrm{BC}}^{\dagger}-\Delta S_{\mathrm{AC}}^{\dagger}=-3 / 2 R \ln \left[2 \pi m_{\mathrm{B}} k T \mathrm{e} / 2 \pi m_{\mathrm{A}} k T \mathrm{e}\right]
$$

When $T$ is constant, Eq. 5 is given by,

$$
\Delta \Delta S_{\mathrm{ABC}}^{\dagger}=-3 / 2 R \ln \left(m_{\mathrm{B}} / m_{\mathrm{A}}\right)
$$

where $m_{\mathrm{A}}$ and $m_{\mathrm{B}}$ take the relative molecular mass $\left(M_{\mathrm{A}}\right.$ and $\left.M_{\mathrm{B}}\right)$ and $\Delta \Delta S_{\mathrm{ABC}}^{\dagger}$ becomes the linear relation $\ln \left(M_{\mathrm{B}} / M_{\mathrm{A}}\right)$. The $\ln \left(M_{\mathrm{B}} / M_{\mathrm{A}}\right)$ can now be replaced with the descriptor $\sigma_{\mathrm{M}}$ as follows,

$$
\begin{aligned}
& \ln \left(M_{\mathrm{B}} / M_{\mathrm{A}}\right)=2.303 \log \left(M_{\mathrm{B}} / M_{\mathrm{A}}\right)=\sigma_{\mathrm{M}} \\
& \Delta \Delta S_{\mathrm{ABC}}^{\dagger} \propto \sigma_{\mathrm{M}}
\end{aligned}
$$

The descriptor $\sigma_{\mathrm{M}}$ is evaluates the van der Waals interaction energy as phys- 
ical adsorption.

The descriptor $\sigma_{\mathrm{es}}$ can be derived from induction and orientation energies: Induction energy is defined by the following equations:

$$
\begin{aligned}
& E_{\text {ind, } \mathrm{AC}}=-\left[\left(\alpha_{\mathrm{A}} \mu_{\mathrm{C}}^{2}+\alpha_{\mathrm{C}} \mu_{\mathrm{A}}^{2}\right)\right] / r_{\mathrm{AC}}^{6} \\
& E_{\text {ind, BC }}=-\left[\left(\alpha_{\mathrm{B}} \mu_{\mathrm{C}}^{2}+\alpha_{\mathrm{C}} \mu_{\mathrm{B}}^{2}\right)\right] / r_{\mathrm{BC}}^{6}
\end{aligned}
$$

$\alpha$ and $\mu$ are polarizability ${ }^{22)}$ and dipole moment, ${ }^{23)}$ respectively. When $r_{\mathrm{AC}}^{6}$ and $r_{\mathrm{BC}}^{6}$ equal $\alpha_{\mathrm{A}} \alpha_{\mathrm{C}}$ and $\alpha_{\mathrm{B}} \alpha_{\mathrm{C}}$, and $\mu_{\mathrm{C}}^{2} / \alpha_{\mathrm{C}}$ is the constant, both $E_{\text {ind, } \mathrm{AC}}$ and $E_{\text {ind, BC }}$ are correlated to $\mu^{2}{ }_{\mathrm{A}} / \alpha_{\mathrm{A}}$ and $\mu_{\mathrm{B}}^{2} / \alpha_{\mathrm{B}}$, respectively.

The descriptor $\sigma_{\mathrm{es}}$ is defined by the following equation,

$$
\sigma_{\mathrm{es}}=\log \left[\left(\mu_{\mathrm{B}}^{2} / \alpha_{\mathrm{B}}\right) /\left(\mu_{\mathrm{A}}^{2} / \alpha_{\mathrm{A}}\right)\right]
$$

The $\mu_{\mathrm{A}}$ of benzene reference is $0.31 D^{24,25)}$ for $\mu_{\mathrm{Csp} 3-\mathrm{H}}$.

$\Delta E_{\text {ind } \mathrm{ABC}}$ is related to $\sigma_{\mathrm{es}}$ and the orientation energy change $\Delta E_{\text {ori, } \mathrm{ABC}}$ is defined by,

$$
\begin{aligned}
& \Delta E_{\text {ind } \mathrm{ABC}} \propto \sigma_{\mathrm{es}} \\
& \Delta E_{\text {ori, } \mathrm{ABC}} \propto \sigma_{\mathrm{es}}
\end{aligned}
$$

The descriptor $\sigma_{\mathrm{es}}$ can be evaluated by both induction and orientation energies, and is identical to the electrostatic interaction energy.

\section{Results and Disscussion}

Relation between Interaction Energy of Substituted Methane-Benzene and Methane-Substituted Benzene Complexes and the Descriptor $\sigma_{M}$ The electrostatic and charge-transfer terms have been reported to be very important based on the primary calculations of $\mathrm{CH} / \pi$ complexes. ${ }^{5,6)}$ However, typical $\mathrm{CH} / \pi$ complexes such as benzene-methane $^{7-9)}$ have been shown primarily of dispersion interactions based on high-level $a b$ initio calculations. The interaction energies were also consistent with the experimental binding energy $D_{\mathrm{o}}$ of benzene- $\mathrm{X}\left(\mathrm{X}=\right.$ methane, ${ }^{10)}$ ethylene and acetylene, ${ }^{26)}$ and benzene ${ }^{27,28)}$ ) as $\mathrm{CH} / \pi$ complexes and benzene- $\mathrm{XH}_{2}\left(\mathrm{X}=\mathrm{N}^{29)}\right.$ and $\left.\mathrm{O}^{30-32)}\right)$ as the T-shape form of hydrogen bonds. Both the calculated and experimental binding energies in the weak interaction showed a linear correlation, as shown in Fig. 1.

Therefore, the high-level ab initio calculation is suitable for the evaluation of the $\mathrm{CH} / \pi$ interaction energy as the dispersion interaction is the major source of the attraction. Results of the calculation suggested that $\sigma_{\mathrm{M}}$ values were good linear relations to the total energy $E_{\text {total }}$ of the typical complexes such as methane-benzene ${ }^{33)}$ and activated complexes such as halomethane-benzene ${ }^{8,34)}$ as shown in Fig. 2. The interaction between the acidic $\mathrm{CH}$ group and $\pi$-electrons in the halomethane-benzene complex was categorized as a conventional $\pi$-hydrogen bond rather than as a van der Waals interaction. ${ }^{35)}$ The large slope observed in Fig. 2 represents the halomethane-benzene series, and the difference between the two slopes accounts for the electrostatic interaction.

The regression analyses of $E_{\text {total }}$ are given by,

$$
\begin{aligned}
& -E_{\text {total }}=5.16(0.51) \sigma_{\mathrm{M}}-2.51(0.47) \\
& n=14, r=0.946, \quad F=102.0, \text { S.D. }=0.17
\end{aligned}
$$

$\left(\mathrm{CH}_{4}-\mathrm{C}_{6} \mathrm{H}_{6}, \quad-\mathrm{C}_{6} \mathrm{H}_{5} \mathrm{Me}, \quad-\mathrm{C}_{6} \mathrm{H}_{4} \mathrm{Me}_{2}, \quad-\mathrm{C}_{6} \mathrm{H}_{3} \mathrm{Me}_{3}, \quad-\mathrm{C}_{10} \mathrm{H}_{8}, \quad \mathrm{C}_{6} \mathrm{H}_{6}-\mathrm{C}_{2} \mathrm{H}_{6}\right.$, $-\mathrm{CH}_{3} \mathrm{NH}_{2},-\mathrm{CH}_{3} \mathrm{OH},-\mathrm{CH}_{3} \mathrm{OCH}_{3},-\mathrm{C}_{6} \mathrm{H}_{6},-\mathrm{C}_{6} \mathrm{H}_{5} \mathrm{CH}_{3},-\mathrm{C}_{6} \mathrm{H}_{5} \mathrm{OH},-\mathrm{C}_{6} \mathrm{H}_{5} \mathrm{~F}$, $-\mathrm{C}_{6} \mathrm{H}_{5} \mathrm{CN}$ )

$$
\begin{aligned}
& -E_{\text {total }}=12.20(0.94) \sigma_{\mathrm{M}}-7.81(0.86) \\
& n=12, r=0.972, \quad F=169.2, \text { S.D. }=0.29
\end{aligned}
$$

$\left(\mathrm{C}_{6} \mathrm{H}_{6}-\mathrm{CH}_{4}, \mathrm{C}_{6} \mathrm{H}_{6}-\mathrm{C}_{2} \mathrm{H}_{4},-\mathrm{C}_{2} \mathrm{H}_{2},-\mathrm{CH}_{3} \mathrm{~F},-\mathrm{CH}_{3} \mathrm{Cl},-\mathrm{CH}_{2} \mathrm{ClNH}_{2},-\mathrm{CH}_{2} \mathrm{ClOH}\right.$, $-\mathrm{CH}_{2} \mathrm{Cl}_{2},-\mathrm{CH}_{2} \mathrm{FCl},-\mathrm{CH}_{2} \mathrm{~F}_{2},-\mathrm{CHCl}_{3},-\mathrm{CHF}_{3}$ )

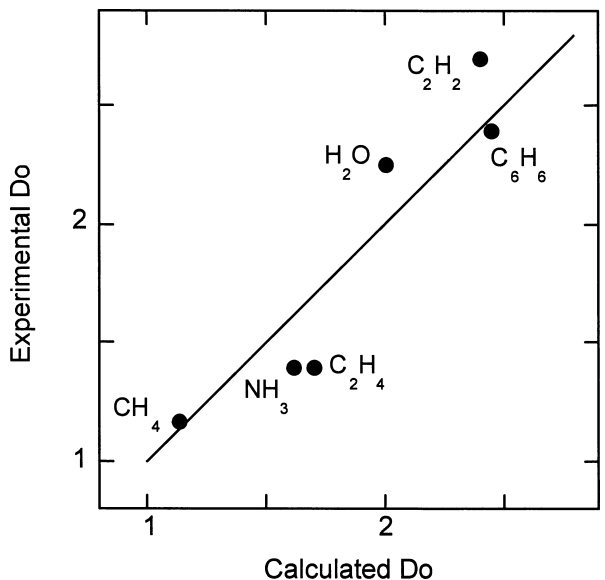

Fig. 1. Correlation between the Calculated and Experimental Binding Energies $D_{\mathrm{o}} / \mathrm{kcal} \mathrm{mol}^{-1}$ with Benzene Complexes

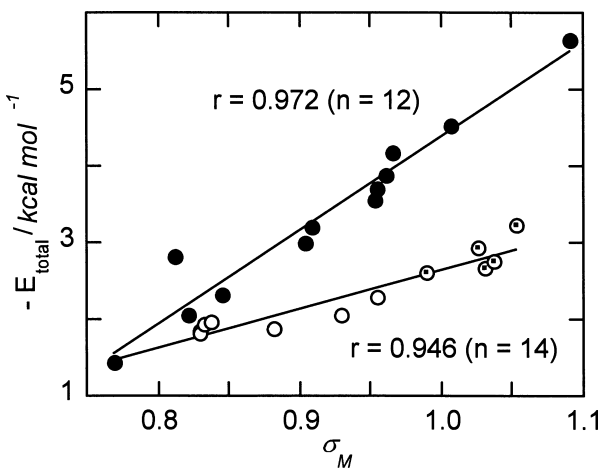

Fig. 2. Plots of $\mathrm{CH} / \pi$ Interaction Energy $E_{\text {total }}$ versus the Descriptor $\sigma_{\mathrm{M}}$

$\bigcirc$, $\bigcirc$ and $\odot$ estimated $E_{\text {total }}$ by Tsuzuki et al. and Morita et al., and by Sinnokrot et $a l .{ }^{38)}$ respectively.

$$
\begin{aligned}
& -E_{\mathrm{total}}=6.82(0.53) \sigma_{\mathrm{M}}-0.82(0.06) E_{\mathrm{es}}-4.11(0.49) \\
& n=25, r=0.976, F=225.5, \text { S.D. }=0.23
\end{aligned}
$$

These findings suggest that the typical and activated $\mathrm{CH} / \pi$ complexes consisted primarily of the dispersion energy $E_{\text {dis }}$ (Eqs. 13, 14). The difference of two groups is $E_{\mathrm{es}}$ and it is negligible small for the typical $\mathrm{CH} / \pi$ complex. The two groups (Eqs.13, 14) could be defined by one equation as in Eq. 15 , since $E_{\text {es }}$ contributed to the activated $\mathrm{CH} / \pi$ complex. The typical $\mathrm{CH} / \pi$ complex differs from the hydrogen bond and the orientation dependence is very small. On the other hand, the activated $\mathrm{CH} / \pi$ complex is close to weak hydrogen bond as $\mathrm{C}_{6} \mathrm{H}_{6}-\mathrm{H}_{2} \mathrm{O}$ etc. ${ }^{36)}$ The descriptors $\sigma_{\mathrm{M}}$ will be compared with the correlation interaction energy $E_{\text {corr }}$ in the following section.

The Relationship between $\boldsymbol{E}_{\text {corr }}$ and $\boldsymbol{\sigma}_{\mathrm{M}}$ The relationship between $E_{\text {corr }}$ and $\sigma_{\mathrm{M}}$ was linear up to relative large energy values in the activated $\mathrm{CH} / \pi$ interaction. The relationship could be described by the following regression analyses, as shown in Fig. 3.

$E_{\text {corr }}=-17.03(1.92) \sigma_{\mathrm{M}}+11.45(1.78)$

$n=9\left(\mathrm{C}_{6} \mathrm{H}_{6}-\mathrm{CH}_{3} \mathrm{~F},-\mathrm{CH}_{3} \mathrm{Cl},-\mathrm{CH}_{2} \mathrm{ClNH}_{2}, \mathrm{CH}_{2} \mathrm{ClOH},-\mathrm{CH}_{2} \mathrm{Cl}_{2},-\mathrm{CH}_{2} \mathrm{FCl}\right.$, $\left.-\mathrm{CHCl}_{3},-\mathrm{C}_{2} \mathrm{H}_{2},-\mathrm{CH}_{4}\right), r=0.958, F=78.9$, S.D. $=0.54$

The $\sigma_{\mathrm{M}}$ is proposed to be representative of the $E_{\text {dis }}$, since the $E_{\text {corr }}$ consists primarily of attractive dispersion energy.

The Relationship between $E_{\text {es }}$ and $\sigma_{\text {es }}$ Hartree-Fock 
(HF) calculation does not depend on the basis set. Therefore, the descriptor $\sigma_{\text {es }}$ values were comparable with the electrostatic energies $E_{\mathrm{es}}$ using MP2/6-31G* $(0.25)$ in pyridine-substituted benzenes complexes ${ }^{37)}$ (Fig. 4).

This regression analyses is given by,

$$
\Delta E_{\mathrm{es}}=-0.23(0.04) \sigma_{\mathrm{es}}-0.08(0.06)
$$

$n=8\left(\mathrm{H}, \mathrm{Me}, \mathrm{OH}, \mathrm{NH}_{2}, \mathrm{CHO}, \mathrm{COOH}, \mathrm{CN}, \mathrm{NO}_{2}\right), r=0.905, F=27.0$, S.D. $=0.09$

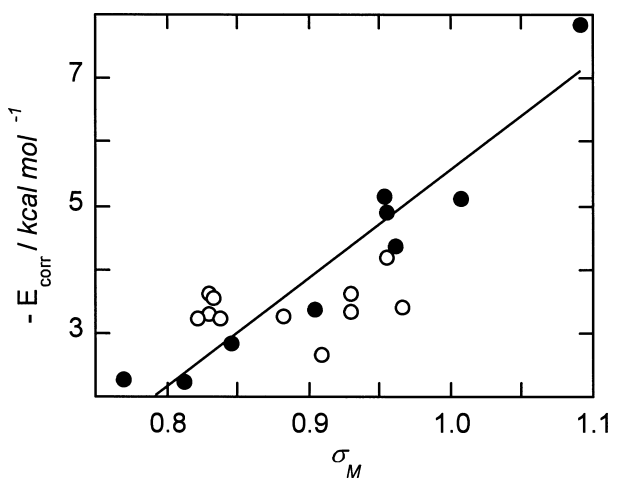

Fig. 3. Correlation between $E_{\text {corr }}$ and the Descriptor $\sigma_{\mathrm{M}}$ in Benzene-Methanes and Methane-Benzenes Complexes

- and $\bigcirc$ are chloro- and substituted compounds, respectively.

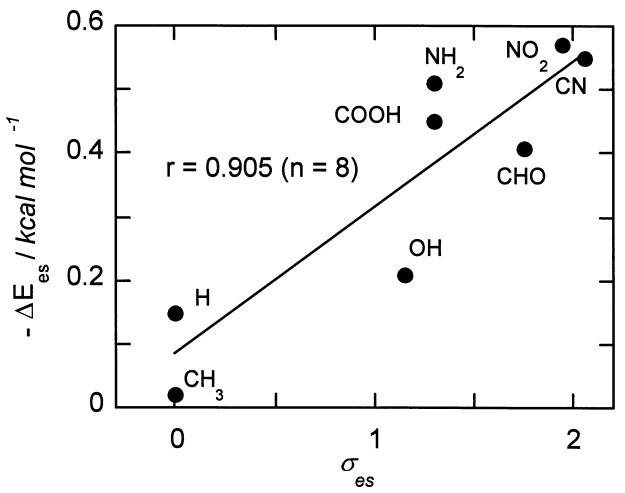

Fig. 4. Correlation between $-\Delta E_{\mathrm{es}}$ of Pyridine-Monosubstituted Benzenes Complexes and the Descriptor $\sigma_{\text {es }}$
The two descriptors $\sigma_{\mathrm{M}}$ and $\sigma_{\mathrm{es}}$ were in good agreement with $E_{\text {corr }}$ and $E_{\text {es }}$ in Eqs. 16 and 17, respectively. Therefore, both descriptors could be used to estimate the relatively weak interaction. Next, regression analyses were carried out using $\sigma_{\mathrm{M}}$ and $\sigma_{\text {es }}$ in the solute-stationary liquid interaction.

The Relation between $\sigma_{\mathrm{M}}$ and $\Delta \Delta \boldsymbol{S}_{\mathrm{s}}^{\circ}$ The activated translational entropy change $\Delta \Delta S^{\dagger}$ derived using Eyring's model could be correlated with $\sigma_{\mathrm{M}}$. Furthermore, these thermodynamic parameters were obtained, because the relative retention values, $\log \gamma$, varied with temperature. If the interactions were based on physical adsorption, the resolution entropy changes $\Delta \Delta S_{\mathrm{s}}^{\circ}$ would be related to $\sigma_{\mathrm{M}}$. The $\Delta \Delta S_{\mathrm{s}}^{\circ}(\mathrm{np})$ values showed a linear relationship for mono-substituted benzenes-squalane under non-polar conditions. (Fig. 5).

These results suggested that the solute-stationary liquid interaction primarily consisted of van der Waals interactions, which was reflected in the physical adsorption. Table 1 shows a list of regression analyses for mono-, 1,3- and 1,4-substituted benzenes under non-polar conditions. The predicted values were fitted to the observed values (Fig. 6).

The $\Delta \Delta S_{\mathrm{s}}^{\circ}$ (sp) values estimated under semi-polar conditions as (dinonyl phthalate) were also analyzed using $\sigma_{\mathrm{M}}$. Furthermore, the values were well fit in addition to descriptor $\sigma_{\text {es }}$. When the stationary phase was polar, the contribution from $\sigma_{\text {es }}$ was significant. The solute-stationary liquid inter-

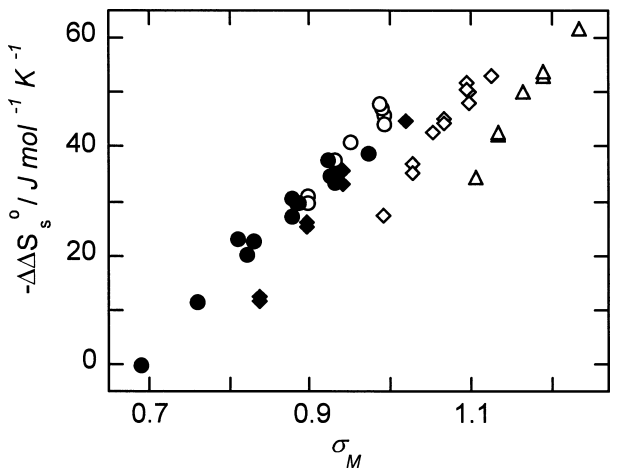

Fig. 5. Correlation between the Entropy Change $\Delta \Delta S_{\mathrm{s}}^{\circ}$ and the Descriptor $\sigma_{\mathrm{M}}$ in Substituted Benzenes

$\boldsymbol{\bullet}=\mathrm{R}, \mathrm{H} ; \diamond=\mathrm{F}, \mathrm{R} ; \mathrm{O}=\mathrm{Cl}, \mathrm{R} ; \diamond=\mathrm{Br}, \mathrm{R} ; \triangle=\mathrm{I}, \mathrm{R}$ compounds.

Table 1. The Results of the Regression Analyses for the Resolution Entropy Changes $\Delta \Delta S_{\mathrm{s}}^{\circ}$ and Relative Retention Values, log $\gamma$, in for the Solute-Squalane Interactions for Substituted Benzenes

\begin{tabular}{|c|c|c|c|c|c|c|c|}
\hline & Coeff. of $\sigma_{\mathrm{M}}$ & Coeff. of $\sigma_{\mathrm{es}}$ & Const. & $n^{a)}$ & $r^{b)}$ & $F^{c)}$ & S.D. ${ }^{d)}$ \\
\hline$-\Delta \Delta S_{\mathrm{s}}^{\circ}$ & $206.64(11.57)$ & & $2.41(1.51)$ & 13 & 0.982 & 296.6 & 2.16 \\
\hline$-\Delta \Delta S_{\mathrm{s}}^{\circ}$ & $190.64(15.18)$ & & $-145.95(13.88)$ & 8 & 0.982 & 157.8 & 2.41 \\
\hline$-\Delta \Delta S_{\mathrm{s}}^{\circ}$ & $165.61(15.05)$ & & $-117.18(14.35)$ & 9 & 0.972 & 121.2 & 1.65 \\
\hline$-\Delta \Delta S_{\mathrm{s}}^{\circ}$ & $195.25(13.74)$ & & $-164.56(14.71)$ & 12 & 0.976 & 201.9 & 1.76 \\
\hline$-\Delta \Delta S_{\mathrm{s}}^{\circ}$ & $206.64(11.57)$ & & $-192.28(13.47)$ & 7 & 0.992 & 318.9 & 1.25 \\
\hline$-\Delta \Delta S_{\mathrm{s}}^{\circ}$ & $143.56 \quad(5.93)$ & & $-98.54 \quad(5.61)$ & 49 & 0.962 & 585.8 & 3.49 \\
\hline \multirow[t]{2}{*}{$\log \gamma$} & $4.308(0.334)$ & & $-2.936(0.288)$ & 13 & 0.968 & 165.9 & 0.089 \\
\hline & $3.934(0.246)$ & $0.087(0.023)$ & $-2.696(0.204)$ & & 0.987 & 190.68 & 0.060 \\
\hline \multirow[t]{2}{*}{$\log \gamma$} & $4.247(0.226)$ & & $-2.935(0.213)$ & 18 & 0.978 & 353.7 & 0.085 \\
\hline & $3.842(0.226)$ & $0.087(0.028)$ & $-2.661(0.194)$ & & 0.987 & 274.2 & 0.068 \\
\hline \multirow[t]{2}{*}{$\log \gamma$} & $4.626(0.254)$ & & $-3.199(0.243)$ & 13 & 0.984 & 332.9 & 0.093 \\
\hline & $4.196(0.217)$ & $0.108(0.031)$ & $-2.953(0.185)$ & & 0.993 & 342.4 & 0.066 \\
\hline \multirow[t]{2}{*}{$\log \gamma$} & $4.942(0.331)$ & & $-3.462(0.317)$ & 24 & 0.954 & 222.5 & 0.143 \\
\hline & $3.959(0.279)$ & $0.179(0.032)$ & $-2.775(0.241)$ & & 0.982 & 277.9 & 0.091 \\
\hline \multirow[t]{2}{*}{$\log \gamma$} & $4.653(0.188)$ & & $-3.236(0.178)$ & 64 & 0.953 & 614.8 & 0.123 \\
\hline & $4.099(0.165)$ & $0.126(0.019)$ & $-2.886(0.145)$ & & 0.973 & 549.9 & 0.094 \\
\hline
\end{tabular}




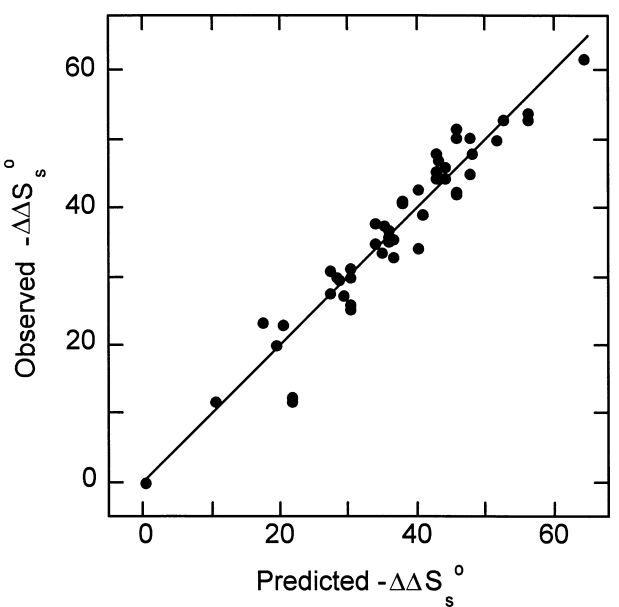

Fig. 6. Correlation between the Predicted and Observed Entropy Changes $\Delta \Delta S_{\mathrm{s}}{ }^{\circ} / J \mathrm{~mol}^{-1} \mathrm{~K}^{-1}$ in Substituted Benzene-Squalane Complexes

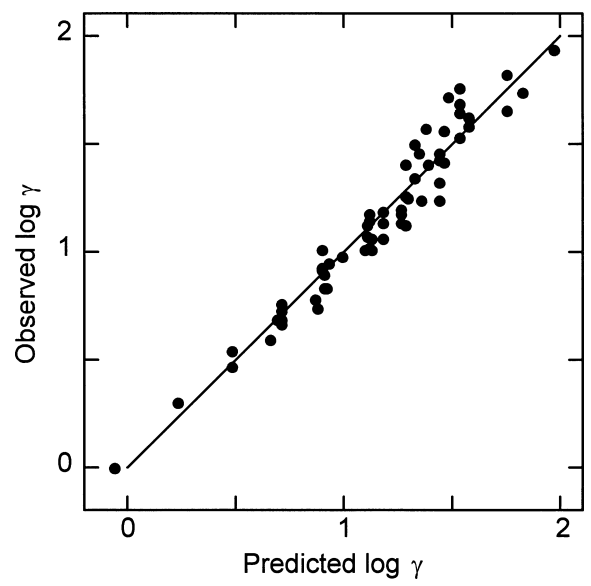

Fig. 7. Correlation between the Predicted and Observed $\log \gamma$ in Substituted Benzene-Squalane Complexes

action however consisted with primarily van der Waals interactions. Further the standard coefficients for $\sigma_{\mathrm{M}}$ were greater than $98 \%$ and $80 \%$ under non- and semi-polar conditions, respectively, in GLC.

$$
\begin{aligned}
& -\Delta \Delta S_{\mathrm{s}}^{\circ}(\mathrm{np})=131.79(7.44) \sigma_{\mathrm{M}}+1.62(0.69) \sigma_{\mathrm{es}}+2.01(1.28) \\
& n=13\left(\mathrm{H}, \mathrm{Me}, \mathrm{Et}, n-\mathrm{Pr}, n-\mathrm{Bu}, \mathrm{OMe}, \mathrm{OEt}, \mathrm{COMe}, \mathrm{COEt}, \mathrm{CO}_{2} \mathrm{Me}, \mathrm{CO}_{2} \mathrm{Et},\right. \\
& \left.\mathrm{CN}, \mathrm{NO}_{2}\right), r=0.988, F=211.0, \mathrm{~S} . \mathrm{D} .=1.82 \\
& -\Delta \Delta S_{\mathrm{s}}^{\circ}(\mathrm{sp})=147.67(9.39) \sigma_{\mathrm{M}}+6.71(0.88) \sigma_{\mathrm{es}}+3.35(1.61) \\
& n=13, r=0.990, F=241.5, \mathrm{~S} . \mathrm{D} .=2.30
\end{aligned}
$$

\section{Regression Analyses of the Relative Retention Value} $\log \gamma$ The relative retention values $\log \gamma$ were analyzed using two descriptors $\sigma_{\mathrm{M}}$ and $\sigma_{\mathrm{es}}$ for mono- and di-substituted benzenes-squalane interactions under non-polar conditions (Table 1).

The observed values for $\log \gamma$ were in good agreement with predicted values (Fig. 7). Therefore, the descriptor $\sigma_{\mathrm{M}}$ is expected to be useful for determining the relative contribution of very weak interactions such as the $\mathrm{CH} / \pi$ interaction.

\section{Conclusion}

The solute-stationary liquid interaction in GLC was determined using Eyring's model to be the physical adsorption.
The descriptor $\sigma_{\mathrm{M}}$ derived using Eyring's model was used to estimate the van der Waals interactions and was in good agreement with the $\mathrm{CH} / \pi$ interaction energy introduced into high-level $a b$ initio calculations. This suggested that the solute-stationary liquid interaction for halo-benzenes consisted primarily of van der Waals interactions under the gas conditions. In other words, the induced macroscopic $\sigma_{\mathrm{M}}$ was correlated with the microscopic high-level calculated energy as the $\mathrm{CH} / \pi$ interaction. Regression analyses of the $\log \gamma$ values were carried out using $\sigma_{\mathrm{M}}$ and the predicted values were determined to be in good agreement with the observed values.

\section{References and Notes}

1) Karle I. L., Butcher R. J., Wolak M. A., Silva F., Dementrio A., Uchida M., Breads J.-L., Kafafi Z. H., J. Phys. Chem., C, 111, 9543-9547 (2007).

2) Sada K., Miyata M., Matsumoto A., Cryst. Growth Des., 3, 247-256 (2003).

3) Matsumoto A., Tanaka T., Tsubouchi T., Tashiro K., Saragai S., Nakamoto S., J. Am. Chem. Soc., 124, 889-902 (2002).

4) Umezawa Y., Nishio M., Bioorg. Med. Chem., 6, 493-504 (1998).

5) Nishio M., Hirota M., Umezawa Y., "The $\mathrm{CH} / \pi$ interaction," WileyVCH, New York, 1998.

6) Sakaki S., Kato K., Miyazaki T., Musashi Y., Ohkubo K., Ihara H., Hirayama C., J. Chem. Soc. Faraday Trans., 89, 659-664 (1993).

7) Tarakeshwar P., Choi H. S., Kim K. S., J. Am. Chem. Soc., 123, 3323-3331 (2001).

8) Tsuzuki S., Honda K., Uchimaru T., Mikami M., Tanabe K., J. Phys. Chem., A, 106, 4423-4428 (2002).

9) Sundararajan K., Sankaran K., Viswandthan K. S., Kulkarni A. D., Gadre S. R., J. Phys. Chem., A, 106, 1504-1510 (2002).

10) Shibasaki K., Fujii A., Mikami N., Tsuzuki S., J. Phys. Chem., A, 110, 4397-4404 (2006).

11) Takahashi O., Kohno Y., Iwasaki S., Saito K., Iwaoka M., Tomoda S., Umezawa Y., Tsuboyama S., Nishio M., Bull. Chem. Soc. Jpn., 74, $2421-2430$ (2001).

12) Meijer E. J., Sprik M., J. Chem. Phys., 105, 8684-8689 (1996).

13) Tsuzuki S., Luthi H. P., J. Chem. Phys., 114, 3949-3957 (2001).

14) Sato T., Tsuneda T., Hirao K., Mol. Phys., 103, 1164-1151 (2005).

15) Glasstone S., Laidler K. J., Eyring H., "The Theory of Rate Processes-The Kinetics of Chemical Reactions, Viscosity, Diffusion and Electrochemical Phenomena-," Chapter VII, McGraw-Hill, Inc., New York, 1941.

16) Kawaki H., Chem. Pharm. Bull., 52, 221-225 (2004).

17) Littlewood A. B., Phillips C. S. G., Price D. T., J. Chem. Soc., 1955, 1480-1489 (1955).

18) Kawaki H., Chem. Pharm. Bull., 41, 797-803 (1993).

19) Kawaki H., Chem. Pharm. Bull., 49, 5-9 (2001).

20) Kawaki H., Sasaki Y., Takagi T., Fujii S., Masuda F., Chem. Pharm. Bull., 37, 3268-3271 (1989).

21) Aoki S., 〈htto://aoki2.si.gumma-u.ac.jp/BlackBox $\rangle$.

22) West R. C., "Handbook of Chemistry and Physics," 70th, ed. by CRC Press. Inc., Boca Raton, Florida, 1989-1990, pp. C4 — C551.

23) McClellan A. L., "Tables of Experimental Dipole Moments," Freeman, San Francisco, 1963.

24) Rollefson R., Havens R., Phys. Rev., 57, 710-717 (1940).

25) Petro A., J. Am. Chem. Soc., 80, 4230 4232 (1958).

26) Shibasaki K., Fujii A., Mikami N., Tsuzuki S., J. Phys. Chem., A, 111, $753-758$ (2007).

27) Grover J. R., Walters E. A., Hui E. T., J. Phys. Chem., 91, 3233-3237 (1987).

28) Lee E. C., Kim D., Jurecka D., Tarakeshwar P., Hobza P., Kim K. S., J. Phys. Chem., A, 111, 3446-3457 (2007).

29) Rodham D. A., Suzuki S., Suenram R. D., Lovas F. J., Dasgupta S., Goddard III, W. A., Blake G. A., Nature (London), 362, 735-737 (1993).

30) Gotch A. J., Zwier T. S., J. Chem. Phys., 96, 3388-3401 (1992).

31) Cheng B.-M., Grover J. R., Walters E. A., Chem. Phys. Lett., 232, 364-369 (1995).

32) Courty A., Mons M., Diminicoli I., Piuzzi F., Dimmicoli I., J. Phys. 
Chem., A, 101, 1445-1450 (1997).

33) Morita S., Fujii A., Mikami N., Tsuzuki S., J. Phys. Chem., A, 110, 10583-10590 (2006).

34) Tsuzuki S., Honda K., Uchimaru T., Mikami N., Fujii A., J. Phys. Chem., A, 110, 10163-10168 (2006).

35) Fujii A., Morita S., Miyazaki M., Ebata T., Mikami N., J. Phys. Chem., $A, \mathbf{1 0 8}, 2652-2658$ (2004).
36) Tsuzuki S., Honda K., Uchimaru T., Mikami M., Tanabe K., J. Am. Chem. Soc., 122, 11450-11458 (2000).

37) Mignon P., Loverix S., DeProft F., Geerling P., J. Phys. Chem., A, 108, 6038-6044 (2004).

38) Sinnokrot M. O., Sherrill C. D., J. Am. Chem. Soc., 126, 7690-7697 (2004). 